\title{
Improving the Durability of Agricultural Machinery Parts by Applying Antifriction Coatings
}

\section{Yakov Nemyrovskyi $^{1 *}$, Ihor Shepelenko ${ }^{2}$ and Olha Medvedieva ${ }^{1}$}

${ }^{1}$ Department of Ecology and Environmental Protection, Central Ukrainian National Technical University, Ukraine

${ }^{2}$ Department of Operation and Repair of Machines, Central Ukrainian National Technical University, Ukraine

*Corresponding Author: Yakov Nemyrovskyi, Department of Ecology and Environmental Protection, Central Ukrainian National Technical University, Ukraine.
Received: March 20, 2020

Published: April 29, 2020

(C) All rights are reserved by Yakov Nemyrovskyi., et al.

\begin{abstract}
An analysis of the literature showed that the problem of increasing the durability of the friction parts of agricultural machinery (AGM) can be successfully solved by applying antifriction coatings on their surface. The analysis of the existing anti-friction coating application schemes showed that the most simple, resource-saving and environmentally friendly is the method of finishing antifriction non-abrasive treatment (FANT). The possibility and feasibility of using FANT with respect to AGM friction units have been proved. To achieve higher performance properties of parts with anti-friction coatings, combined processing using FANT and deforming broaching is proposed. Using cylinder liners as an example, it is proved that the use of the proposed technology improves the working capacity and durability of rubbing parts of AGM, thereby increasing the life of tribo-joints of mobile AGM and can be recommended both in the manufacture and in the restoration of friction parts of mobile agricultural machines.

Keywords: Agricultural Machinery; Durability; Anti-Friction Coating; Finishing Anti-Friction Non-Abrasive Treatment; Deforming Broaching
\end{abstract}

\section{Abbreviations}

AGM: Agricultural Machinery; FANT: Finishing Anti-Friction NonAbrasive Treatment; AC: Antifriction Coatings; DB: Deforming Broaching

\section{Introduction}

The effectiveness of agricultural machinery (AGM) is largely dependent on its reliability and durability. Downtime caused by its repair and maintenance leads to a delay in the agro-technical timeframe for the implementation of field work and, as a result, to a loss of crop yield.

The quality of AGM operated in agriculture does not meet the requirements, as a result of which the cost of their repair and maintenance exceeds the cost of production.

It was established [1] that the reliability of AGM depends on the materials and technologies used in the repair production, and the low durability of the units is a consequence of their insufficient wear resistance, as a result of which the resource of AGM is significantly reduced, and the production of agricultural products decreases.

It has been proved [2] that the performance and life of the AGM is determined by the wear rate of the rubbing parts, with about $80 \%$ of the details of agricultural machines fail due to wear. Therefore, by choosing the coating material of the wearing parts and the technology of its application correctly, it is possible to significantly increase the wear resistance and durability of the friction parts of AGM.

As is known [3], in recent years, the issue of ecology and environmental protection has become an acute issue. The content and emission of harmful components increases sharply during the operation of worn-out engines of mobile AGM, which leads to pollution of agricultural lands, a decrease in the quantity and quality of products, and, in general, environmental degradation.

Consequently, the issues of improving the quality of friction parts of AGM and improving the ecology of the environment are both modern and relevant tasks.

\section{Materials and Methods}

The analysis of works [4-6] shows that the search for ways to increase the durability of the rubbing parts of mobile agricultural equipment occurs mainly in three directions: design, technological and operational.

The main directions for increasing the durability of AGM during their design are as follows: optimization of structural schemes of machines and joints, selection of durable materials of parts and their rational combination in friction pairs, ensuring optimal conditions for their work (load, speed) with minimal friction losses and others [4]. 
The high quality of manufacturing parts of AGM during its production depends on the implementation of the following main technological measures [5]:

- $\quad$ Ensuring the necessary precision in the manufacture of parts and the optimal quality of their work surfaces;

- Hardening by thermal, chemical-thermal treatment and surface plastic deformation;

- Drawing of wear-resistant, corrosion-resistant and other protective coatings on the surface of parts by galvanic and chemical methods;

- $\quad$ Surfacing, gas-thermal spraying;

- Application of antifriction coatings on the surface of parts.

The operating conditions of agricultural machines have a great impact on their reliability [6]. In this regard, operational measures should also be given due consideration.

The problem of increasing the durability of AGM friction parts can be successfully solved by applying antifriction coatings (AC) [7]. In [8], it was pointed out that from the point of view of increasing reliability and service life, it is necessary that each part, including AGM, regardless of the material of manufacture, have a protective coating in accordance with its intended purpose and operating conditions. The author [9] proposed a classification of AC types according to a positive depth gradient of properties, which for a long time served as a guide in the development of new, more advanced types of coatings. In [10], the systematization of the available information on the methods of applying AC to the metal surfaces of parts by compiling their classifications from various positions was performed, which allows a reasoned approach to the choice of the method of obtaining AC.

An analysis of the existing AC application schemes $[10,11]$ showed that the most simple method that does not require expensive equipment, and most importantly, is environmentally friendly, is the method of finishing anti-friction non-abrasive treatment (FANT), which implements a selective transfer mode in the friction unit. The essence of selective transfer lies in the fact that under certain conditions there is a selective dissolution of the surface layer of the metal of the part, due to its interaction with lubricants and the friction surfaces of the "counterbody" are coated with a special protective skin, called "servo" [12].

The feasibility of using FANT as applied to AGM units was convincingly proved in [13-15], which lists a wide list of friction units for combine harvesters and other mobile agricultural machinery.

The use of FANT makes it possible to increase the wear resistance of parts by 1.5 - 2 times, improve the antifriction and extreme pressure properties of rubbing surfaces, reduce the running-in time, and, in general, increase the durability of agricultural machines by $30 \%$.

However, the efficiency of the FANT process at the moment is not high enough, especially when operating in conditions of high specific loads, when the skin coating quickly fails. In addition, stable coating formation is limited by a certain initial roughness of the base surface of $0.08<\mathrm{Ra}<1.5 \mu \mathrm{m}$ [16].

To improve the quality of the coating, and, consequently, the durability of the friction parts, is possible by combining FANT with methods of surface plastic deformation. In this case, it is more expedient to use the combination and localization of the impact on the treated surface of the deforming and rubbing elements [11].

It should be noted that a number of requirements are made to AC, regardless of the methods of their formation, the main of which should be attributed [10]:

- $\quad$ Density and continuity;

- High adhesion to the metal surface;

- Uniform coating thickness and a sufficiently high cleanliness of its surface;

- $\quad$ Ability, together with the base metal, to withstand operational loads.

Thus, to achieve higher performance properties of parts, the most effective seems to be the combined processing method using FANT and surface plastic deformation, combining the advantages of these methods.

The aim of the present work is to develop a combined technology for applying anti-friction coatings using FANT to increase the durability of parts of AGM.

The resource of AGM internal combustion engines is determined mainly by the state of the cylinder-piston group, which account for from 45 to $60 \%$ of all failures, due to insufficient wear resistance of the friction parts that make them up. Therefore, one of the ways to increase the resource of new and repaired engines of agricultural machines is to increase the wear resistance of parts that limit the resource of engines. These details include cylinder liners, made, as a rule, of gray cast iron grade $\mathrm{SCh}$.

In this paper, we propose a technology for processing the inner surface of cylinder liners using FANT.

\section{Results and Discussion}

The use of FANT in the processing of cylinder liners will allow: to reduce the running-in time of parts by 1.5 - 2 times, to exclude the seizure of friction surfaces of parts, increase the bearing capac- 
ity of parts and joints, protect the friction surface from hydrogen wear, reduce the friction temperature and extend the period of operation of the friction unit when switching off the lubricant supply, reduce the friction coefficient and thereby reduce the internal combustion engine fuel consumption to $3 \%$, etc.

Despite the indisputable advantages, the existing FANT technology of cylinder liners has not found wide application, primarily because of the low productivity of the process and the quality of the coating. Based on this, it is advisable to introduce research to improve the friction-mechanical methods of FANT, to increase the efficiency of their use.

One of the directions for improving FANT is work aimed at improving process productivity and processing quality through the use of combined technologies [18].

In our opinion, the problem of increasing the productivity and quality of FANT of cylinder liners can be solved using the capabilities of deforming broaching (DB) (Figure 1), which is traditionally used to obtain increased dimensional accuracy and surface roughness, improve the strength of the press mating parts and sealing the surface layer. The features of the processing of DB should include [19]:

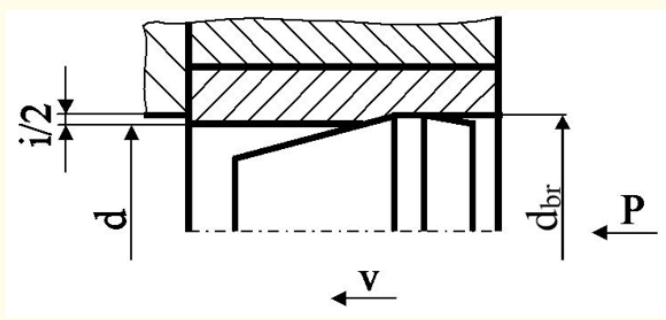

Figure 1: Diagram of the DB process: i- Tension; P- Broaching Force; v- Broaching Speed; d- Diameter of the Hole; dbr- Broach Diameter

- Maintaining the integrity of the metal fibers improves all of its operational characteristics;

- Combination of small roughnesses with hardening of the surface layer and the ability to guarantee the receipt of residual compressive stresses provides high performance properties of parts, especially under cyclic loads;

- $\quad$ Providing roughness with a large supporting surface increases wear resistance, accelerates the running-in and improves friction conditions;

- Decrease in the surface roughness Ra from 4.0 to $0.05 \mu \mathrm{m}$ in one pass classifies the DB process as one of the most productive;

- Absence of sharpening, which is inevitable with all types of abrasive processing, allows you to keep the surface of even soft ductile metals (copper, aluminum) uninfected, which in some cases is a prerequisite;
- Simplicity of the design of carbide deforming broaches and debugging of the process itself, as well as its reliability make it possible to carry out DB in virtually any production.

The use of DB will improve the quality of adhesion of the coating to the base, strengthen the surface layer, increase the bearing capacity and wear resistance of the work surface of the part for a longer period.

Thus, the proposed process for processing cylinder liners consists of the following operations:

- Mechanical processing;

- Application of FANT coating;

- Deformation broaching.

Operational tests showed that the application of FANT coatings with subsequent deformation broaching provides a decrease in the wear of the friction surface of cylinder liners by 1.4 - 1.6 times, which indicates an increase in the resource of the cylinder-piston group of mobile AGM engines.

\section{Conclusion}

The developed resource-saving and environmentally friendly technology for applying anti-friction coatings FANT of cylinder liners using DB helped to reduce wear on the surface of the part, reduce the cost of their restoration, as well as increase the life of the cylinder-piston group of mobile AGM engines during operation and can be recommended both in manufacturing and in the restoration of friction parts of agricultural machines. The use of the proposed technology improves the performance and durability of rubbing parts in AGM, thereby increasing the life of the tribological couplings of the mobile AGM, and in the future will allow the replacement of parts from expensive non-ferrous alloys with cast iron parts with antifriction coating.

\section{Bibliography}

1. Groshev LM., et al. "Reliability of agricultural machinery". Kiev, Harvest (1990): 192.

2. Klenin NI and Egorov VG. "Agricultural and reclamation machines". Moscow, Kolos (2005): 464.

3. Andronov VA., et al. "Environmental safety of the state: state management dimension: monograph". Kharkiv, Nutsu (2016): 220.

4. Rybak TI., et al. "Modern methods of increasing the structural reliability of agricultural machinery". Kiev, Technika (1991): 120.

5. Chernovol MI. "Restoration and strengthening of agricultural machinery parts”. Kiev, UMK VO (1989): 256.

6. Chernovol MI., et al. "Reliability of agricultural machinery". Kirovohrad COD (2010): 320. 
7. Balabanov VI., et al. "Tribotechnology in the technical service of machines". Moscow, Emerald (2005): 192.

8. Karp IN and Nazarenko VG. "Wear resistance and protective coatings (Review)". Ecotechnologies and Resource Conservation 6 (2007): 24-39.

9. Kutkov AA. "Wear-resistant and anti-friction coatings". Moscow, Mechanical Engineering (1976): 152.

10. Chernovol MI and Shepelenko IV. "Methods of forming antifriction coatings on metal friction surfaces". Collection of scientific papers of Kirovograd National Technical University "Engineering in agricultural production, industry engineering, automation" 25.1 (2012): 3-8.

11. Chernovol MI and Shepelenko IV. "Devices for friction-mechanical coating". Collection of Scientific Papers of Kirovograd National Technical University 26 (2013): 58-62.

12. Garkunov DN. "Tribotechnology (wear and wearlessness)". Moscow, ICCA (2001): 616.

13. Katkov DS. "Improving the durability of friction units of mobile agricultural machinery using tribotechnical methods: Ph.D. thesis. Saratov (2008): 227.

14. Chernovol MI., et al. "Effectiveness increase in application of FANT of components of mobile agricultural machines". Collection of scientific papers of the Kirovograd National Technical University "Design, production and operation of agricultural machines" 45.1 (2015): 10-13.

15. Shepelenko IV., et al. "Improvement of finishing antifriction treatment without abrasive of the rubbing parts surfaces of agricultural machineries". International Journal of Agricultural Research, Innovation and Technology (IJARIT) 4.1 (2014): 98101.

16. Shepelenko IV., et al. "The mechanism of formation of antifriction coatings by employing friction-mechanical method". Problems of Tribology 1 (2019): 35-39.

17. Shepelenko IV and Cherkun VV. "Improving the process of finishing anti-friction non-abrasive machining of pinions of hydraulic pumps gears". RRM (Repair. Restoration. Modernization) 9 (2012): 32-35.

18. Chernovol MI., et al. "The combined method of treatment of friction surfaces". Engineering in agricultural production, branch engineering, automation, Kirovograd, KNTU 24.2 (2011): 13-16.

19. Nemyrovskyi Ya., et al. "Technical-Economic Aspects of the Use of Technological Process of Deforming Broaching". Advances in Design, Simulation and Manufacturing II. DSMIE 2019. Lecture Notes in Mechanical Engineering. Springer, Cham (2019): 238-247.

\section{Assets from publication with us}

- Prompt Acknowledgement after receiving the article

- Thorough Double blinded peer review

- Rapid Publication

- Issue of Publication Certificate

- High visibility of your Published work

Website: www.actascientific.com/

Submit Article: www.actascientific.com/submission.php Email us: editor@actascientific.com

Contact us: +919182824667 